\title{
$\beta$ Blockade in congestive heart failure: persistent adverse haemodynamic effects during chronic treatment with subsequent doses
}

\author{
Marrick L Kukin, Jill Kalman, Michael M Mannino, Cathleen Buchholz-Varley, \\ Ofelia Ocampo
}

\begin{abstract}
Objective-To determine whether the acute adverse haemodynamic effects of $\beta$ blockade in patients with congestive heart failure persist during chronic treatment. Design-Sequential haemodynamic evaluation of heart failure patients at baseline and after three months of continuous treatment with the $\beta_{1}$ selective antagonist metoprolol.
\end{abstract}

Setting-Cardiac care unit in university hospital.

Patients-26 patients with moderate to severe congestive heart failure (New York Heart Association grade II to IV) and background treatment with digoxin, diuretics, and angiotensin converting enzyme inhibitors, and with a left ventricular ejection fraction $<25 \%$.

Methods-Baseline variables included a six minute walk, maximum oxygen consumption, and right heart catheterisation. All patients received metoprolol $6.25 \mathrm{mg}$ orally twice daily initially and the dose was gradually increased to a target of $50 \mathrm{mg}$ twice daily. Haemodynamic measurements were repeated after three months of treatment, both before (trough) and after drug readministration.

Results-Long term metoprolol had functional, exercise, and haemodynamic benefits. It produced decreases in heart rate, pulmonary capillary wedge pressure, and systemic vascular resistance, and increases in cardiac index, stroke volume index, and stroke work index. However, when full dose metoprolol was readministered during chronic treatment, there was a reduction in cardiac index (from 2.8 (SD $0.46)$ to $\left.2.3(0.38) 1 / \mathrm{min} / \mathrm{m}^{2}, \mathrm{p}<<0.001\right)$ and stroke work index (from 31.4 (11.1) to $\left.26.6(10.0) \mathrm{g} . \mathrm{m} / \mathrm{m}^{2}, \mathrm{p}<0.001\right)$ and an increase in systemic vascular resistance (from 943 (192) to 1160 (219) dyn.s.cm ${ }^{-5}$, p $<<0.001$ ).

Conclusions-Adverse haemodynamic effects of $\beta$ blockers in heart failure persist during chronic treatment, as shown by worsening haemodynamic indices with subsequent doses.

(Heart 1997;78:444-449)

Keywords: heart failure; $\beta$ blockers; adverse effects

New York, New York 10029,

USA; email: marrick

kukin@SMTPlink.mssm.edu

Accepted for publication 24 June 1997
There is increasing evidence that chronic $\beta$ adrenergic blockade in congestive heart failure ${ }^{1}$ produces long term haemodynamic, ${ }^{2-4}$ and functional improvements ${ }^{5-7}$ and may provide survival benefits. ${ }^{8-10}$ Activation of the sympathetic nervous system occurs early in heart failure-presumably as a response to a decrease in cardiac output. The initial $\beta$ adrenergic stimulation augments myocardial contractility to maintain stroke volume, and through peripheral arteriolar vasoconstriction assists the maintenance of blood pressure and vital organ perfusion. However, continuous and sustained sympathetic nervous system activation may be cardiotoxic and play an important role in the progression of congestive heart failure.

The use of $\beta$ blockers to treat heart failure is fraught with difficulty. Minute doses of $\beta$ blockers are used when initiating treatment in order to minimise the risk of acute haemodynamic compromise. However, even the administration of low doses of $\beta$ blockers has adverse haemodynamic effects through decreasing cardiac output and increasing systemic vascular resistance. These adverse effects generally do not cause significant clinical deterioration but may require dose adjustments of diuretics or angiotensin converting enzyme (ACE) inhibitors. Gradual titration of increasing $\beta$ blocker dosage is achieved over several weeks (with concomitant adjustments of diuretics and ACE inhibitors as clinically indicated) to achieve the target dose of $\beta$ blockers.

There has been no previous study of whether the acute adverse haemodynamic effects with initial low dose $\beta$ blocker treatment persist in patients with heart failure during long term treatment when "full" target doses are given. The objective of the present study was therefore to evaluate whether patients on chronic $\beta$ blocker treatment still show haemodynamic compromise with each subsequent dose of $\beta$ blocker despite the long term haemodynamic and clinical improvements found with chronic $\beta$ blockade.

\section{Methods}

PATIENT POPULATION

Eligible patients had severe chronic heart failure with symptoms of persistent dyspnoea and fatigue at rest or on exertion (New York Heart Association class II to IV) despite intensive treatment with digoxin, diuretics, and an ACE inhibitor. All patients were enrolled while clinically stable without evidence of peripheral oedema, having received no intravenous diuretics for at least two weeks before baseline 
evaluation. Patients were excluded from the study if they had experienced an acute myocardial infarct within six weeks or an acute exacerbation of heart failure within two weeks, had a history of obstructive lung disease or claudication, a systolic blood pressure less then $85 \mathrm{~mm}$ $\mathrm{Hg}$, or a resting heart rate less than 64 beats/min. The study was approved by the institutional review board and patients signed informed consent before enrolment into the study.

\section{STUDY DESIGN}

Following this stabilisation period, each patient's clinical status was assessed by a review of symptoms and by determination of the New York Heart Association (NYHA) functional class. Each patient underwent a six minute walk test to assess submaximal exercise endurance $^{11}$ and bicycle ergometry with gas exchange to assess peak maximum oxygen consumption. ${ }^{12}$ Right heart catheterisation was performed to measure intracardiac pressures, using an internal jugular approach under local anaesthetic and fluoroscopic guidance, with a triple lumen flow directed thermodilution catheter (Argon Maxxim Medical, Athens, Texas, USA).

The next morning, baseline haemodynamic measurements were determined in the fasting state. ${ }^{13}$ Three complete sets of haemodynamic measurements (right atrial, pulmonary artery, and pulmonary capillary wedge pressures) with four determinations of thermodilution cardiac output with iced injectate (Baxter Edwards Clinical Care Division, Model COM 2P-115, Irvine, California, USA) were obtained five to 10 minutes apart for baseline values. Blood pressure determinations were made by electronic cuff measurements. A maximum of $10 \%$ variation was allowed between the last two baseline measurements before proceeding with the protocol. A baseline left ventricular filling pressure of $\geqslant 14 \mathrm{~mm} \mathrm{Hg}$ was required for continuation in the study. The third set of measurements was then used for the reported baseline value. Measurements were obtained while the patient was lying still in bed. If Cheyne-Stokes respirations were present, measurements were taken during the apnoeic period. All haemodynamic measurements were made by one of two research nurse practitioners (CB-V or OO). All cardiac medications (digoxin, diuretics, and ACE inhibitors) were withheld either for 12 hours (for twice daily or thrice daily schedules) or for 24 hours (for once daily schedules) before the haemodynamic evaluations for that day, except for the test drug (metoprolol) as indicated.

Derived haemodynamic variables were calculated as follows: cardiac index $(\mathrm{CI})=$ cardiac output $(\mathrm{CO}) /$ body surface area $\left(1 / \mathrm{min} / \mathrm{m}^{2}\right)$, systemic vascular resistance $(\mathrm{SVR})=80 \times(\mathrm{MAP}$ - MRAP)/CO (dyn.s. $\mathrm{cm}^{-5}$ ), stroke volume index $(\mathrm{SVI})=\mathrm{CI} / \mathrm{HR}\left(\mathrm{ml} / \mathrm{m}^{2}\right)$, and stroke work index $(\mathrm{SWI})=($ MAP $-\mathrm{PCW}) \times \mathrm{SVI} \times 0.0136$ (g. $\left.\mathrm{m} / \mathrm{m}^{2}\right)$, where MAP $=$ mean arterial pressure, $\mathrm{MRAP}=$ mean right atrial pressure, $\mathrm{HR}$ $=$ heart rate, and PCW = pulmonary capillary wedge pressure.
Blood was collected from the indwelling catheter side port for the measurement of plasma noradrenaline after the patients had rested in the supine position for at least 30 minutes. Serum was frozen, shipped, and analysed by high performance liquid chromatography (Smith Kline Beecham Clinical Laboratories, Norristown, Pennsylvania, USA).

The primary objective of our study was to evaluate whether patients on chronic $\beta$ blocker treatment showed haemodynamic compromise with each subsequent dose of $\beta$ blocker. The protocol was modified after the first 13 patients had been enrolled to allow haemodynamic data to be obtained following the initial administration of low dose metoprolol for comparative purposes. Thus half of the patients received $6.25 \mathrm{mg}$ of metoprolol and all haemodynamic variables were redetermined every 30 minutes for three hours on day 1 . All 26 patients were discharged home on metoprolol $6.25 \mathrm{mg}$ orally twice daily (metoprolol tartrate, Ciba Geigy: recompounded by hospital research pharmacist for doses of up to 12.5 twice daily; subsequent doses given by prescription). $\mathrm{Pa}-$ tients were seen once a week over the subsequent four week period. Metoprolol was increased to 12.5 twice daily, $25 \mathrm{mg}$ twice daily, and $50 \mathrm{mg}$ twice daily sequentially each week if the previous dose was tolerated. If there were significant signs or symptoms of bradycardia, orthostasis, or worsening congestive heart failure, the dose was held constant or reduced and re-evaluated for increase on the following visit. Diuretics were adjusted when there was evidence of fluid retention.

After three months of continuous treatment, all clinical and exercise assessments were repeated. A repeat right heart catheterisation was performed for measurement of intracardiac pressures in an identical manner to the initial haemodynamic evaluation. The following morning, long term baseline haemodynamic measurements were determined in the fasting state before the metoprolol dose (trough). All other cardiac drugs were withheld until the completion of haemodynamic readings for that day. After the next scheduled full dose of oral metoprolol was given, haemodynamic variables were measured every 30 minutes for three hours in all patients completing the protocol. Blood was again collected from the indwelling catheter for the measurement of plasma noradrenaline after the patients had rested in the supine position for at least 30 minutes.

\section{STATISTICAL ANALYSIS}

Baseline haemodynamic characteristics of the patients were compared with the acute haemodynamic measurements (for 13 patients) and with the long term measurements (before the next dose of metoprolol) using Student's $t$ test for paired data for all patients completing the study. Chronic next dose comparisons are between long term trough and long term peak for the patients who completed the study ( $\mathrm{n}=$ 22). A repeated measure analysis of variance was used to assess the significance of the differences for each haemodynamic variable of the 
Table 1 Baseline and acute haemodynamic data at two hours after receiving metoprolol $6.25 \mathrm{mg}$ for 13 patients entering the haemodynamic study

\begin{tabular}{|c|c|c|c|}
\hline Haemodynamic measurement & Baseline & Acute peak & $p$ value * \\
\hline Heart rate (beats/min) & (10.7) & $92 \quad(11.4)$ & NS \\
\hline Mean arterial pressure $(\mathrm{mm} \mathrm{Hg})$ & (12.6) & $(9.8)$ & NS \\
\hline Pulmonary capillary wedge pressure $(\mathrm{mm} \mathrm{Hg})$ & $(5.8)$ & $(5.2)$ & NS \\
\hline Right atrial pressure $(\mathrm{mm} \mathrm{Hg})$ & $11 \quad(5.1)$ & $12(4.9)$ & NS \\
\hline Cardiac index $\left(1 / \mathrm{min} / \mathrm{m}^{2}\right)$ & $2.2(0.35)$ & $1.9(0.37)$ & 0.0009 \\
\hline Systemic vascular resistance (dyn.s. $\mathrm{cm}^{-5}$ ) & 1367 (340) & 1580 & 0.0019 \\
\hline Stroke volume index $\left(\mathrm{ml} / \mathrm{m}^{2}\right)$ & $23.6(4.87)$ & $20.5(4.16)$ & 0.0011 \\
\hline Stroke work index $\left(\mathrm{g} \cdot \mathrm{m} / \mathrm{m}^{2}\right)$ & $16.9(5.1)$ & $15.1(5.05)$ & 0.0234 \\
\hline
\end{tabular}

Values are expressed as mean (SD)

${ }^{\star}$ Significant difference within each haemodynamic parameter from trough to peak, with analysis of variance correction for repeated measures.

completers at baseline, long term trough, and long term peak. Group data are expressed as means (SD). All haemodynamic variables measuring peak effect of drug are reported as the readings from two hours after the drug was given (to avoid a bias in evaluating drug effect). Two hours was chosen as a pharmacological approximation of full absorption of metoprolol.

\section{Results}

Twenty six patients entered the study. Three patients were NYHA class II, 18 were class III, and five were class IV. All patients had a left ventricular ejection fraction of less than $25 \%$ as assessed by radionuclide ventriculography, ranging from $6 \%$ to $23 \%$ with a mean of $13 \%$. There were 21 men and five women. Their ages ranged from 29 to 72 years of age, with a mean of 49 years. The cause of heart failure was ischaemic heart disease in seven patients, primary cardiomyopathy in 18 , and valvar cardiomyopathy in one.

All patients were receiving oral frusemide, average total daily dose 130 (104) mg. Four of the patients were also on supplemental metolazone. Before enrolment in the study, each patient had been taking constant doses of digoxin and an ACE inhibitor for at least four weeks. All patients were receiving ACE inhibitors: nine were receiving captopril, average total daily dose 96 (42.4) mg, 10 were receiving enalapril, average total daily dose $21(11.2) \mathrm{mg}$, six were receiving lisinopril, average total daily dose 15 (5.5) $\mathrm{mg}$, and one was receiving quinapril, $40 \mathrm{mg}$ daily. All patients were receiving digoxin, average daily dose $0.21(0.06) \mathrm{mg}$.

Twenty two patients completed the protocol and the long term haemodynamic evaluation. Two patients did not tolerate low dose metoprolol and withdrew from the study. One patient died suddenly. One patient underwent transplant before the three month evaluation. Nineteen completers reached the target dose of metoprolol $50 \mathrm{mg}$ twice daily; three patients received $25 \mathrm{mg}$ twice daily because of intolerance at the higher dose.

CLINICAL RESPONSE

Overall, long term treatment with metoprolol was associated with significant functional and exercise improvements. NYHA class (as a continuous variable) improved from 3.1 to 2.0 $(\mathrm{p}<<0.001)$ and by one functional class when categorised as a dichotomous variable $\left(\chi^{2}\right.$, $\mathrm{p}<<0.001)$. Measurements of both submaxi- mal and maximum exercise capacity showed significant improvements. Distance on the six minute walk increased from 1151 (275.4) to 1295 (381.8) feet ( $\mathrm{p}<<0.001)$; and peak maximum oxygen consumption from 12.3 (3.6) to $16.1(4.5) \mathrm{ml} / \mathrm{kg} / \mathrm{min}(\mathrm{p}=0.0012)$.

Ejection fraction increased from $12.4(4.87) \%$ to $17.6(6.95) \% \quad(\mathrm{p}<<0.001)$. Measurements of noradrenaline concentrations showed a significant decrease from 702 (314.7) to $416(221.4) \mathrm{pg} / \mathrm{ml}(\mathrm{p}=0.0056)$.

\section{HAEMODYNAMIC VARIABLES}

Acute haemodynamic effects of low dose $\beta$ blocker Even at the minute dose of $6.25 \mathrm{mg}$ metoprolol, there were significant adverse haemodynamic effects (table $1, \mathrm{n}=13$ ). Cardiac index decreased by $0.3 \mathrm{1} / \mathrm{min} / \mathrm{m}^{2}(\mathrm{p}<0.001)$ and systemic vascular resistance increased by 213 dyn.s. $\mathrm{cm}^{-5}(\mathrm{p}=0.0019)$. Consequently, stroke volume index declined by $3.1 \mathrm{ml} / \mathrm{m}^{2}(\mathrm{p}=$ 0.0011 ) and stroke work index decreased by $1.8 \mathrm{~g} \cdot \mathrm{m} / \mathrm{m}^{2}(\mathrm{p}=0.0234)$.

Chronic haemodynamic effects (trough)

Continuous treatment with metoprolol had significant long term haemodynamic benefits when measured before the next scheduled dose of metoprolol (trough), in addition to the clinical benefits described above. For those completing the study, resting heart rate decreased from $94(11.2)$ to 74 (13.7) beats $/ \mathrm{min}$ ( $\mathrm{p}<<0.001)$, pulmonary capillary wedge pressure decreased from $28(7.0)$ to $21(8.2) \mathrm{mm}$ $\mathrm{Hg}(\mathrm{p}<0.001)$, and cardiac index increased from $2.3(0.52)$ to $2.8(0.46) \quad 1 / \mathrm{min} / \mathrm{m}^{2}$ $(\mathrm{p}<0.001)$. Systemic vascular resistance decreased from 1259 (301) to 943 (192) dyn.s. $\mathrm{cm}^{-5}(\mathrm{p}<0.001)$. Importantly, stroke volume index increased from 24.5 (6.9) to 39.8 (11.7) $\mathrm{ml} / \mathrm{m}^{2}(\mathrm{p}<<0.001)$ and stroke work index from $18.7(7.5)$ to $31.4(11.1) \mathrm{g} . \mathrm{m} / \mathrm{m}^{2}$ $(\mathrm{p}<<0.001)$. These haemodynamic results concur with other $\beta$ blocker trials in moderate to severe congestive heart failure.

\section{Next dose chronic haemodynamic effects (trough} to peak)

In order to determine the subsequent haemodynamic effects of full dose metoprolol after three months of continuous treatment, measurements were compared between long term baseline and two hours after the next scheduled full dose of metoprolol for all patients who completed the protocol (50 mg in 19 patients, $25 \mathrm{mg}$ in three patients). The $\mathrm{p}$ values represent the differences between long term baseline and long term peak. When the next full dose of metoprolol was given, heart rate declined by a further 3.6 beats $/ \mathrm{min}$ ( $\mathrm{p}=$ $0.0125)$. Cardiac index decreased by 0.5 $1 / \mathrm{min} / \mathrm{m}^{2}$ ( $\left.\mathrm{p}<<0.001\right)$, while systemic vascular resistance increased by 217 dyn.s. $\mathrm{cm}^{-5}$ $(\mathrm{p}<<0.001)$. Furthermore, stroke volume index decreased by $5.8 \mathrm{ml} / \mathrm{m}^{2}(\mathrm{p}<<0.001)$ and stroke work index by 4.8 g.m $/ \mathrm{m}^{2}$ $(\mathrm{p}<0.001)$, as shown in table 2 .

These changes are shown graphically for three time points (baseline, long term trough after three months of metoprolol treatment, 
Table 2 Long term baseline (trough) and two hour post next dose (peak) haemodynamic data following three months of continuous metoprolol treatment in all patients completing the haemodynamic study $(n=22)$

\begin{tabular}{lcccll}
\hline Haemodynamic measurement & $\begin{array}{l}\text { Long term } \\
\text { trough }\end{array}$ & $\begin{array}{l}\text { Long term } \\
\text { peak }\end{array}$ & p value \\
\hline Heart rate (beats/min) & 74 & $(13.7)$ & 71 & $(13.6)$ & 0.0125 \\
Mean arterial pressure (mm Hg) & 78 & $(9.3)$ & 79 & $(13.6)$ & $\mathrm{NS}$ \\
Pulmonary capillary wedge pressure $(\mathrm{mm} \mathrm{Hg})$ & 21 & $(8.2)$ & 22 & $(8.5)$ & $\mathrm{NS}$ \\
Right atrial pressure $(\mathrm{mmHg})$ & 9 & $(6.1)$ & 10 & $(5.7)$ & $\mathrm{NS}$ \\
Cardiac index $\left(1 / \mathrm{min}^{2}\right)$ & $2.8(0.46)$ & $2.3(0.38)$ & 0.0001 \\
Systemic vascular resistance $\left(\right.$ dyn.s. $\left.\mathrm{cm}^{-5}\right)$ & $943(192)$ & 1160 & $(219)$ & 0.0001 \\
Stroke volume index $\left(\mathrm{ml} / \mathrm{m}^{2}\right)$ & $39.8(11.66)$ & $34.0(10.36)$ & 0.0001 \\
Stroke work index $\left(\mathrm{g} \cdot \mathrm{m} / \mathrm{m}^{2}\right)$ & $31.4(11.06)$ & $26.6(9.97)$ & 0.0002 \\
\hline
\end{tabular}

Values are mean (SD).

* Significant difference within each haemodynamic variable from trough to peak, with analysis of variance correction for repeated measures.
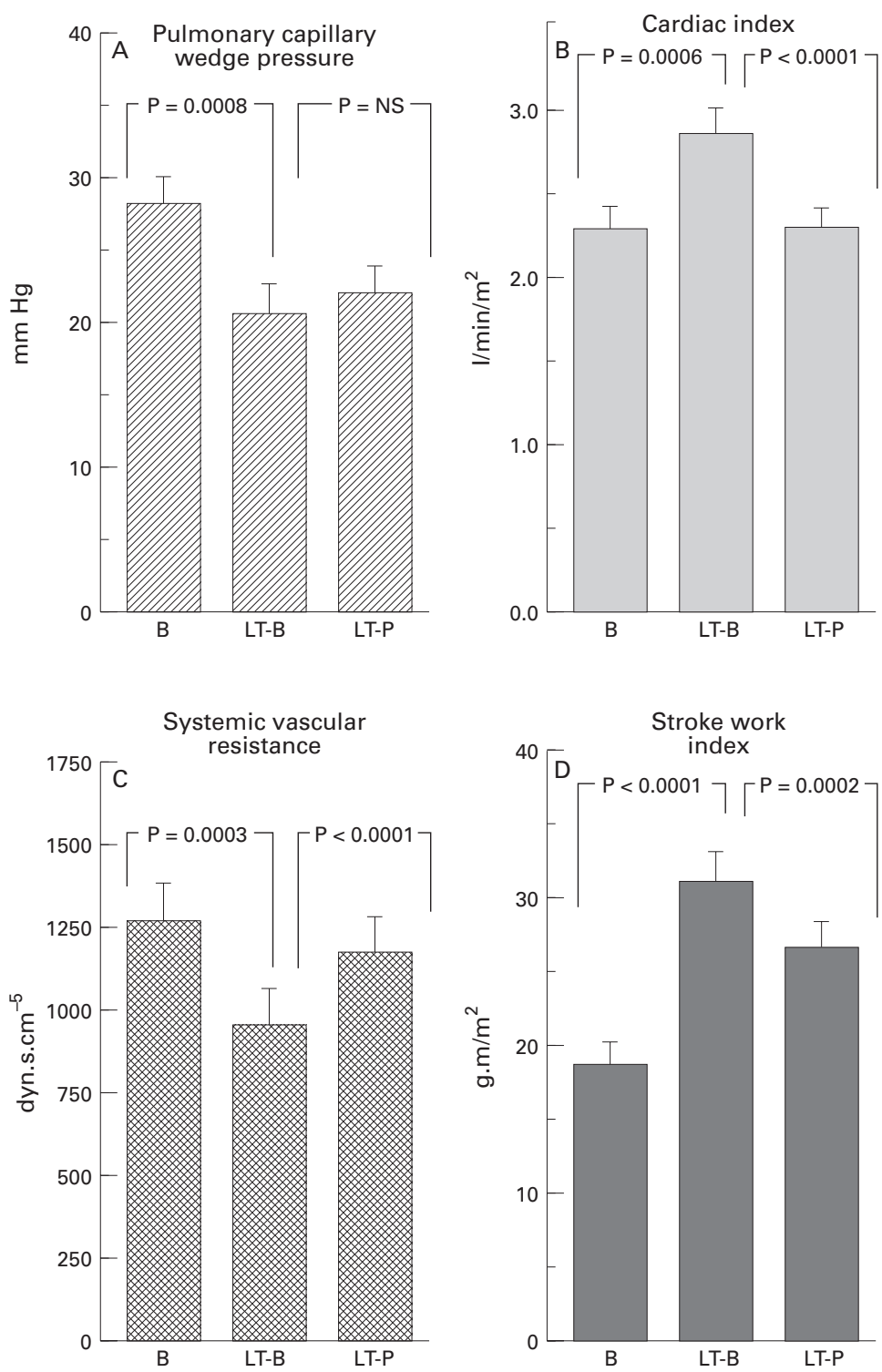

Figure 1 Haemodynamic indices of $(A)$ pulmonary capillary wedge pressure, $(B)$ cardiac index, $(C)$ systemic vascular resistance, and (D) stroke work index at baseline (B), long term trough after three months of metoprolol treatment (LT-B), and two hours after drug readministration (LT-P). Error bars are SEM. $P$ values are designated to show differences from $B$ to $L T-B$ and from $L T-B$ to $L T-P$ for the 22 completers.

and two hours after drug readministration) in fig 1 for the 22 patients who completed the protocol. Despite these adverse haemodynamic effects with full dose metoprolol, there were no clinical manifestations of worsening congestive heart failure with the next dose.

\section{Discussion}

Despite the known adverse acute haemodynamic effects of $\beta$ blockade, there is increasing evidence that chronic $\beta$ blockade provides long term haemodynamic, symptomatic, exercise, and perhaps survival benefits in patients with moderate to severe congestive heart failure. Because of the negative haemodynamic effects of $\beta$ blockers in heart failure, treatment is initiated with minute doses and only gradually increased over the course of several weeks, with concomitant adjustment of diuretics and ACE inhibitors as needed. Given the problems associated with starting $\beta$ blocker treatment and the accumulating evidence for a beneficial long term response, we investigated whether the initial negative haemodynamic effects dissipated during the course of chronic $\beta$ blocker treatment.

Our patients showed significant long term haemodynamic improvements before the next dose of drug (trough period) following a minimum of two months of treatment at target dose. However, each subsequent full dose of metoprolol produced a significant decline in cardiac index, stoke volume index, and stroke work index, with an increase in systemic vascular resistance.

Review of published data from other haemodynamic trials shows similar adverse haemodynamic effects with the next chronic dose of $\beta$ blocker. Metra et a ${ }^{14}$ compared carvedilol to placebo in 40 patients with idiopathic dilated cardiomyopathy, and measured haemodynamic variables during rest and exercise. After three months of chronic treatment, a comparison of haemodynamic measurements obtained at baseline (predrug: trough) and three hours after drug readministration in the carvedilol group showed a decline in cardiac index and stroke volume index, with an increase in systemic vascular resistance. It is important to note that even with these next dose adverse haemodynamic effects, most long term peak measurements (that is, stroke work index and stroke volume index) do show a significant improvement compared to the baseline (pre- $\beta$ blocker treatment) values.

Similarly, in the study of carvedilol by Krum et $a l,{ }^{4}$ the cardiac index did not increase during chronic treatment. In their study, long term haemodynamic evaluation was obtained after administration of the next scheduled dose of carvedilol. In the study by Olsen et $a l^{15}$ there was again no improvement in cardiac index or systemic vascular resistance during chronic administration. These measurements were also obtained after giving carvedilol. Finally, in the MDC (metoprolol in dilated cardiomyopathy) trial, ${ }^{16}$ there was no significant long term improvement in cardiac index, presumably because the measurements were taken after administration of the next scheduled dose of metoprolol (it was not clearly specified in the methods section of the paper when the readings were obtained). 
The pathophysiology of these haemodynamic phenomena has similarities to the $\beta$ blocker withdrawal syndrome. ${ }^{17-20}$ A possible explanation for this syndrome is $\beta$ blocker induced receptor upregulation ${ }^{21}$ and subsequent adrenergic hypersensitivity after drug withdrawal. In classic abrupt $\beta$ blocker withdrawal, there is a differential rate of decline between receptor density and plasma concentration of the $\beta$ blocker producing a milieu for adrenergic hyperresponsiveness. In chronic congestive heart failure, $\beta$ receptor downregulation occurs and is related to the degree of ventricular dysfunction. Other studies have shown that chronic treatment with metoprolol increases myocardial receptor density ${ }^{22-24}$ and is associated with a significant increase in $\beta$ agonist responsiveness. This receptor upregulation may provide the environment for the persistence of adverse haemodynamic effects of chronic full dose $\beta$ blocker and thereby account for the significant differences between peak and trough haemodynamic indices. However, unlike metoprolol, carvedilol does not cause $\beta$ receptor upregulation. ${ }^{25} 26$ Since similar chronic haemodynamic effects have been documented with carvedilol, , $^{41526}$ as are shown in this study with metoprolol, it is doubtful whether $\beta$ receptor upregulation fully explains these results.

A more likely mechanism of this phenomenon may be that there is a balance between the negative haemodynamic properties of metoprolol (presumably acting as a negative inotrope) because of adrenergic withdrawal and a beneficial effect of blocking noradrenaline (thereby chronically improving left ventricular function). Even after three months of continuous metoprolol treatment, the negative haemodynamic effects are still measurable with the next dose (peak), albeit in the context of an overall net haemodynamic and clinical benefit of chronic metoprolol treatment.

It is possible that the persistent adverse haemodynamic effects may be minimised with the use of longer acting $\beta$ blockers, with subsequent diminution in the variation of plasma drug concentration. Either explanation (the withdrawal phenomenon or the precarious balance between a negative haemodynamic and a blocking effect against "toxic" levels of noradrenaline) may partially explain the failure of metoprolol to produce a decrease in mortality in the MDC trial. ${ }^{16}$ With metoprolol in MDC, there was a statistically non-significant trend of increasing sudden death which may be due to a heightened effect of adrenergic stimulation before the next dose of the drug.

\section{LIMITATIONS OF THE STUDY}

We did not measure inotropy or contractility of the ventricle. Our results are based on haemodynamic indices which reflect loading conditions as well as contractility. Additionally, there is no control group, but we are describing a phenomenon of adverse haemodynamic effects with subsequent dosing of chronic metoprolol treatment. In stable patients, there is minimal haemodynamic change over the course of two hours while on bed rest without food or vasoactive drugs. We do not have serum drug concentrations to explore the possible differences between peak and trough drug concentrations. However, these are limitations to a more complete understanding of the mechanism of adverse haemodynamic response to $\beta$ blocker treatment that we are describing, but do not detract from the reported observations.

\section{CONCLUSIONS}

In conclusion, this study confirms the beneficial haemodynamic, clinical, and exercise benefits of $\beta$ blocker treatment in a population with moderate to severe heart failure. The persistent adverse haemodynamic effects of each subsequent dose of the drug may be accentuated by variations in plasma drug concentrations. Given these adverse effects, the timing of haemodynamic measurements in relation to the next scheduled dose of the drug should be considered in reporting these variables. Haemodynamic indices reported from a "trough" period may be quite different from those in a "peak" period with $\beta$ blocker treatment. As can be seen in this study, the improvement in cardiac index with long term metoprolol treatment is only significant if chronic trough measurements are used for comparison. If only the measurements taken two hours after the next dose of metoprolol were used for comparison, there would be no measurable improvement in cardiac index. The most dramatic benefits for all haemodynamic variables are seen when comparing baseline to the long term trough measurements. These adverse haemodynamic indices probably reflect an alteration of the delicate balance between the negative haemodynamic properties of metoprolol and the beneficial effect of blocking noradrenaline. The exact mechanism of these adverse effects and their possible modulation with longer acting $\beta$ blockers requires further study.

We thank Marilyn Steinmetz MA for conducting the exercise portion of this study.

1 Waagstein F, Hjalmarson A, Varnauskas E, Wallen I. Effect of chronic beta-adrenergic receptor blockade in congestive cardiomyopathy. Br Heart F 1975;37:1022-36.

2 Heilbrunn SM, Shah P, Bristow MR, Valentine HA, Ginsburg R, Fowler MB. Increased beta-receptor density and improved hemodynamic response to catecholamine stimulation during long-term metoprolol therapy in heart failure from dilated cardiomyopathy. Circulation 1989;79: 483-90.

3 Gilbert EM, Anderson JL, Deitchman D, Yanowitz FG, O'Connell JB, Renlund DG, et al. Long term $\beta$-blocker vasodilator therapy improves cardiac functio illated cardiomyopathy: a double-blind, randomized study Am F Med 1990;88:223-9.

4 Krum H, Sackner-Bernstein JD, Goldsmith RL, Kukin ML, Schwartz B, Penn J, et al. Double-blind, placebo controlled study of the long-term efficacy of carvedilol in patients with severe chronic heart failure. Circulation 1995;92:1499-506.

5 Englemeier RS, O'Connell JB, Walsh R, Rad N, Scanlon PJ, Gunnar RM. Improvement in symptoms and exercise tolerance by metoprolol in patients with dilated cardiomyopathy. A double-blind, randomized, placebo-controlled trial. Circulation 1985;72:536-46.

6 Anderson B, Blomstrom-Lundqvist C, Hedner T, Waagstein F. Exercise hemodynamics and myocardial metabolism during long-term beta-adrenergic blockade in severe heart failure. $\mathcal{F}$ Am Coll Cardiol 1991;18:1059-66.

7 Currie PJ, Kelly MJ, McKenzie A, Harper RW, Lim YL, Federman J, et al. Oral beta-adrenergic blockade with metoprolol in chronic severe dilated cardiomyopathy. $f \mathrm{Am}$ Coll Cardiol 1984:3:230-9.

8 Swedburg K, Hjalmarson A, Waagstein F, Wallentin I. Prolongation of survival in congestive cardiomyopathy by beta-receptor blockade. Lancet 1979; i:1374-6. 
9 Swedberg K, Hjalmarson A, Waagstein F, Wallentin I. Beneficial effects of long-term beta-blockade in congestive cardiomyopathy. Br Heart f 1980;44:117-33.

10 Packer M, Bristow MR, Cohn JN, Colucci WS, Fowler MB, Gilbert EM, et al for the US Carvedilol Heart Failure Study Group. The effect of carvedilol on morbidity and mortality in patients with chronic heart failure. $N$ Engl $f$ Med 1996;334:1349-55.

11 Guyatt GH, Sullivan MJ, Thompson PJ, Fallon EL, Pugsley SO, Taylor DW, et al. The six-minute walk: a new measure of exercise capacity in patients with chronic heart failure. Can Med Assoc 7 1985;132:919-23.

12 Weber KT, Janicki JS, McElroy PA. Determination of aerobic capacity and the severity of chronic cardiac and circulatory failure. Circulation 1987;76(suppl 6):VI-40-5.

13 Packer M, Medina N, Yushak M. Hemodynamic changes mimicking a vasodilator drug response in the absence of drug therapy after right heart catheterization in patients with chronic heart failure. Circulation 1985;71:761-6.

14 Metra M, Nardi M, Giubbini R, Dei Cas L. Effects of shortand long-term carvedilol administration on rest and and long-term carvedilol administration on rest and exercise hemodynamic variables, exercise capacity and clinical conditions in patients with idiopathic dil

15 Olsen S1, Gilbert EM, Renlund DG, Taylor DO, Yanowitz FD, Bristow MR. Carvedilol improves left ventricular function and symptoms in chronic heart failure: a doubleblind randomized study. F Am Col Cardiol 1995;25:122531.

16 Waagstein F, Bristow MR, Swedberg K, Camerini F, Fowler $\mathrm{MB}$, Silver MA, et al for the MDC Trial Study Group. Beneficial effects of metoprolol in idiopathic dilated cardiomyopathy. Lancet 1993;342:1441-6.

17 Miller RR, Olson HG, Amsterdam EA, Mason DT. Propranolol-withdrawal rebound phenomenon: Exacerbation of coronary events after abrupt cessation of antianginal therapy. $N$ Engl f Med 1975;293:416-8.
18 Bristow $M$. The adrenergic nervous system in heart failure. N Engl F Med 1984;311:850-1.

19 Swedberg K, Hjalmarson A, Waagstein F, Wallentin I. Adverse effects of beta-blockade withdrawal in patients with congestive cardiomyopathy. Br Heart $\mathcal{F}$ 1980;44:13442.

20 Waagstein F, Caidahl K, Wallentin I, Bergh CH, Hjalmarson A. Long-term $\beta$-blockade in dilated cardiomyopathy: effects of short and long-term metoprolol treatment followed by withdrawal and readministration of metoprolol. Circulation 1989;80:551-63.

21 Davies AO, Lefkowitz RJ. Regulation of adrenergic receptors. In: Lefkowitz RJ, ed. Receptor regulation. London: Chapman and Hall, 1981:83-122.

22 Fowler MB, Laser JA, Hopkins GL, Minobe W, Bristow MR. Assessment of the $\beta$-adrenergic receptor pathway in the intact failing human heart: progressive receptor downregulation and subsensitivity to agonist response. Circulation 1986;74:1290-302.

23 Bristow, MR, Ginsburg R, Minobe W, Cubicciotti RS, Sageman WS, Lurie K, et al. Decreased catecholamine sensitivity and $\beta$-adrenergic-receptor density in failing sensitivity and $\beta$-adrenergic-receptor density

24 Rassmussen R, Shah P, Larrabee P, Murray J, Ginsburg R, Renlund DG, et al. Beta1 and beta2 receptor downregulation associated with beta agonist administration in
the failing human heart [abstract]. Circulation 1987;76:IVthe faili.

25 Bristow MR, Larrabee P, Muller-Beckmann B, Minobe W, Roden R, Skerl L, et al. Effects of carvedilol on adrenergic receptor pharmacology in human ventricular myocardium and lymphocytes. Clin Invest 1992;70:S10-13.

26 Gilbert EM, Abraham WT, Olsen S, Hattler B, White M, Mealy $\mathrm{P}$, et al. Comparative hemodynamic, left ventricular functional, and antiadrenergic effects of chronic treatment with metoprolol versus carvedilol in the failing heart. Circulation 1996;94:2817-25. 